\title{
Influence of Local Deformation Mode of Cable-Stayed Bridge on Unballasted Tracks: Experimental Research
}

\author{
Xingwang Sheng, ${ }^{1}$ Weiqi Zheng $\left(\mathbb{D},{ }^{1}\right.$ Jianxian $\mathrm{Wu}^{2,3}$ and Handong ${ }^{2 h a n g}{ }^{2,3}$ \\ ${ }^{1}$ School of Civil Engineering Central South University, Changsha 410075, China \\ ${ }^{2}$ Changjiu Intercity Railway Co. Ltd., Nanchang 330002, China \\ ${ }^{3}$ Jiangxi Corporation of Shanghai-Kunming High Speed Railway, Nanchang 330000, China \\ Correspondence should be addressed to Weiqi Zheng; wqzheng@csu.edu.cn
}

Received 24 October 2019; Revised 26 December 2019; Accepted 11 January 2020; Published 18 February 2020

Academic Editor: Fabrizio Paolacci

Copyright (c) 2020 Xingwang Sheng et al. This is an open access article distributed under the Creative Commons Attribution License, which permits unrestricted use, distribution, and reproduction in any medium, provided the original work is properly cited.

\begin{abstract}
The complex local deformation modes of the cable-stayed bridge influence the deformation characteristics of the unballasted tracks laid on it. In this work, a large-scale segment model of a cable-stayed bridge was fabricated, and the maximum upward bending deformation mode of the cable-stayed bridge was realized by multipoint loading on the segment model to study the deformation behaviors of the unballasted tracks. Experimental results indicated that the nonlinear behaviors of the rubber isolation layers are apparent with the loading increased, and the interlayer behaviors of the unballasted track can be improved by the rubber isolation layer. Besides, the relative tensile deformations at interlayers of the unballasted track are inevitable. It is noted that no void and silt form at interlayers of the unballasted tracks with rubber isolation layers due to the precompressions of the rubber material. However, it is entirely possible to produce some diseases such as voids and silts at interlayers of the unballasted track with the geotextile isolation layers paved on the cable-stayed bridge. Furthermore, it is feasible to use the elastic isolation layer to improve the interlayer deformation characteristics because a particular elastic buffer is provided at interlayers of the unballasted track.
\end{abstract}

\section{Introduction}

High-speed railway has made brilliant achievements in the past decades due to its great convenience. As one of the common track types, the unballasted track has been widely applied in high-speed railway engineering duo to its obvious advantages in economy, stability, and durability, especially in China, Japan, and Europe $[1,2]$. Typically, Germany mainly adopts Rheda and Zublin double-block-type unballasted tracks, and Japan mainly adopts unit-plate-type unballasted tracks in Shinkansen line. However, due to the complex geographical conditions and long railway mileages, China adopts several types of unballasted tracks (China Railway Track System), including the continuous slab tracks and the unit-plate-type unballasted tracks [3]. Meanwhile, with the increase of train running speed and axle load, higher requirements in environmental friendliness, stability, and durability are put forward for the unballasted tracks.

Numerous studies have been or are being carried out and reported on the mechanical performances [4-6] and the fatigue or dynamic behaviors [7-9] of various types of unballasted tracks. Unfortunately, these unballasted tracks used for research are almost paved on roadbeds or commonspan bridges. For the unballasted track paved on cablestayed railway bridges, its deformation characteristic is affected by the deformations of the cable-stayed bridges, which distinguish it from the unballasted track paved on the roadbed [10]. To the best of our knowledge, the unballasted track has never been laid on the long-span cable-stayed bridges in practical engineering by now. As a result, this related topic is absent in the literature. Furthermore, a number of cable-stayed bridges have been constructed to 
cross large rivers and valleys with the high-speed railway lines extend [3]. Therefore, it is inevitable to lay unballasted tracks on the high-speed railway cable-stayed bridges.

Moreover, the long-span cable-stayed bridge is a flexiblesystem bridge, and its deformation characteristics are complex and diverse. Therefore, the performances of the unballasted tracks paved on the cable-stayed bridge need to be researched in-depth. Besides, it is worth noting that the excessive transitions between the unballasted tracks and the ballasted tracks are brought out due to the different track types laid on the long-span bridge and its approach bridges. These transitions inevitably bring a lot of inconveniences, including the reduction of rail alignment characteristics and the increase of maintenance work, as well as the higher operation management costs. Thus, it has excellent social and economic benefits to unify the track types used in the long-span cable-stayed bridges and the common-span bridges. In other words, laying unballasted tracks on the cable-stayed bridge is a worthwhile solution.

For the large-scale structure, it is a common way to carry out the experimental research on its segment models, and this is reliable and effective [11-15]. Based on this, a segment model of a cable-stayed bridge was fabricated in the laboratory, and a series of full-scale unballasted tracks were paved on the segment model. Moreover, the finite element analysis of the cable-stayed bridge was realized, and a kind of the local deformation modes labeling the maximum upward bending deformation condition was selected for further research in this work. Furthermore, the maximum upward bending deformation condition of the cable-stayed bridge was obtained by multipoint loading on the segment model. Meanwhile, the interlayer deformations were summarized to explore the deformation characteristics of the unballasted tracks, which are used to lay on the high-speed railway cablestayed bridges.

\section{Test Preparation}

2.1. Engineering Background. Ganjiang River Bridge was a new-designed cable-stayed bridge with the main span of $300 \mathrm{~m}$ (Figure 1), which was located in Chang-Ji-Gan PDL of China high-speed railway. The bridge scheme of the steelconcrete composite girder cable-stayed bridge was first used in the construction of high-speed railway engineering. In order to reduce the influence of the beam deformation on the rail smoothness, some structural improvements were adopted, including the design of the composite girder structures and the setting of auxiliary piers in the side-span.

At present, the unballasted tracks widely used can be divided into two categories: the unit-plate-type unballasted tracks and the continuous slab tracks [3]. Typically, the unitplate-type unballasted tracks are always used to pave on the long-span bridges [16], including the double-block-type unballasted tracks and the CRTS III-type unballasted tracks. The deformation characteristics of these types of unit-platetype unballasted tracks are almost the same because the same limit structures are adopted. Besides, a traditional unit-platetype unballasted track usually consists of rails, track slab, isolation layer, and basement (Figure 2). As one of the most common railway elastic elements in unit-plate-type unballasted tracks, the isolation layers play important roles such as supporting, adjusting, load transferring, and improving the durability of the unit-plate-type unballasted tracks $[17,18]$. As a result, the reasonable application of the isolation layer can reduce the influence on the unballasted tracks caused by the complex local deformation conditions of cable-stayed bridges.

2.2. Description of the Segment Model. In order to simulate the local deformation conditions of the cable-stayed bridge named Ganjiang River Bridge, a segment model of Ganjiang River Bridge was fabricated in the laboratory. The segment model was a simplification of the steel-concrete composite girder of Ganjiang River Bridge. Besides, the segment model was simply supported with a span arrangement of $6+12+6 \mathrm{~m}$, including a beam segment of the main girder between the two adjacent cables and two cantilever sections for loading. There were two supporting conditions underneath the segment model: one was rigid support, and the other was elastic support, which is used to reflect the elastic support characteristics of the main girder. In detail, the rigid support condition was realized by two concrete piers, and the elastic support condition was realized by a transverse steel beam, which is specially designed for these purposes. Moreover, the segment model was $1.5 \mathrm{~m}$ in height and $10 \mathrm{~m}$ in width, which is enough to lay two lines of unballasted tracks on the deck of the segment model. The structures of the segment model and the arrangement of the unballasted tracks used in this work are shown in Figure 3.

At present, the commonly used isolation layers include the geotextile isolation layer and the EPDM rubber isolation layer $[19,20]$. That is, the geotextile isolation layer and the EPDM rubber isolation layer were employed in the unballasted tracks for further research. The thickness of the geotextile isolation layer was $4 \mathrm{~mm}$, and the specifications met the requirements in China relevant codes and standards [21]. Currently, there were various product specifications depending on the thickness and rigidity of the EPDM rubber isolation layers. Therefore, a series of the EPDM rubber isolation layers with a thickness of $27 \mathrm{~mm}$ and a bedding stiffness of $0.025 \mathrm{~N} / \mathrm{mm}^{3}$ were employed in the unballasted tracks in this work. The EPDM rubber isolation layers were composed of two layers, including a layer of plate-like rubber structure with the thickness of $10 \mathrm{~mm}$ and an elastic layer with the thickness of $17 \mathrm{~mm}$, which is composed of a set of evenly arranged circular truncated cone rubber (Figure 4). In addition, the unballasted tracks were directly cast in situ on the segment model (Figure 5), and the unballasted tracks and the concrete deck of the segment model were connected by embedded steel bars.

In this work, a series of unit-plate-type unballasted tracks were used to study furthermore for the purpose of paving on the cable-stayed bridges in high-speed railway engineering. The unit-plate-type unballasted tracks used in this work can be divided into four categories according to their length and isolation layer types, and there were two unballasted tracks in each category. The four categories of unballasted tracks are listed in Table 1, the location of each 

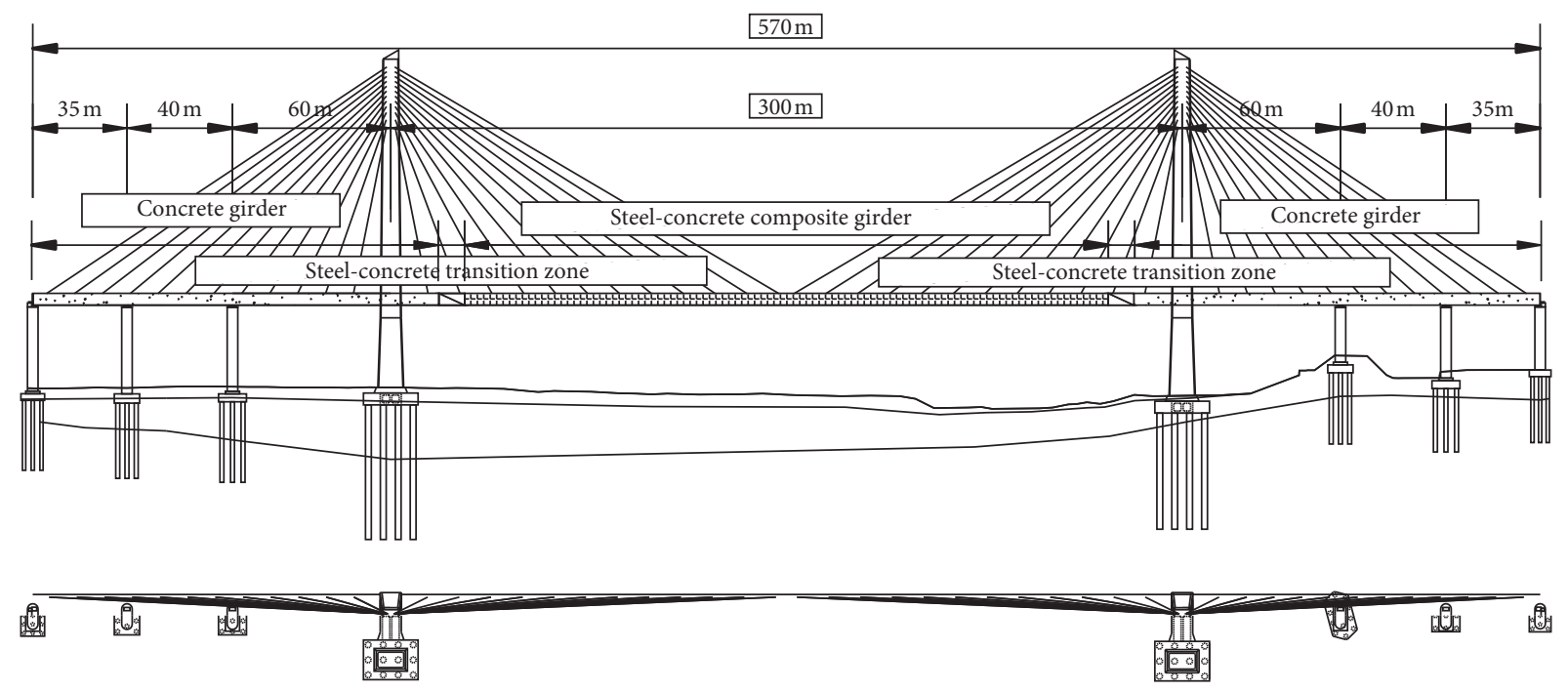

프민 Steel-concrete composite girder

Figure 1: Layout of Ganjiang River Bridge.

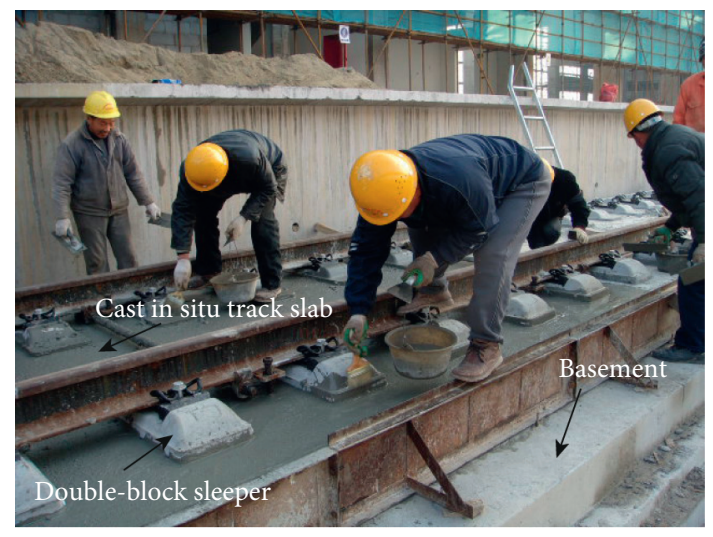

(a)

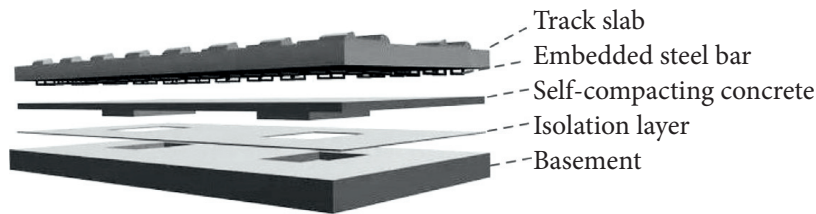

(b)

FIGURE 2: The unit-plate-type unballasted tracks. (a) Double-block-type unballasted track. (b) CRTS III-type unballasted track.

unballasted track is shown in Figure 3, and the unballasted tracks with different types of isolation layers are shown in Figure 6.

\section{Test Procedure}

3.1. Deformation Characteristics of the Cable-Stayed Bridge. The cable-stayed bridges are deformed under the external loads during the service period, and these deformations can be divided into two separate parts according to their characteristics. A part of the deformation can be considered as the overall deflection of the main girder (Figure 7(a)). The other part is the relative deformation between the two adjacent cables of the main girder, that is, the local deformation of the beam segment, which is relative to the suspension points of the cables in the main girder (Figure $7(\mathrm{~b})$ ). The unballasted tracks the on cable-stayed bridge can be deformed synchronously with the main girder under the action of the overall deflection. Therefore, the overall deflection of the main girder can be considered as a kind of longwavelength track irregularity. The influence of the overall deflection on the unballasted track paved on the cable-stayed bridge is similar to that paved on the roadbed with the irregular foundation settlement. Some relevant indexes about the track smoothness can be used to evaluate the influence of the overall deflection on the unballasted tracks paved on cable-stayed bridges [16]. However, the local deformation conditions of the beam segment between the two adjacent cables are always complex and diverse, and they can affect the deformation characteristics of the unballasted tracks paved on cable-stayed bridges. Furthermore, the inconsistency of deformations may be formed between the unballasted tracks and the main girder under the local deformation conditions, and it always leads to the formation of diseases in the unballasted tracks, which should be paid more attention.

The local deformation of the beam segment can be divided into several deformation modes, including the upward 


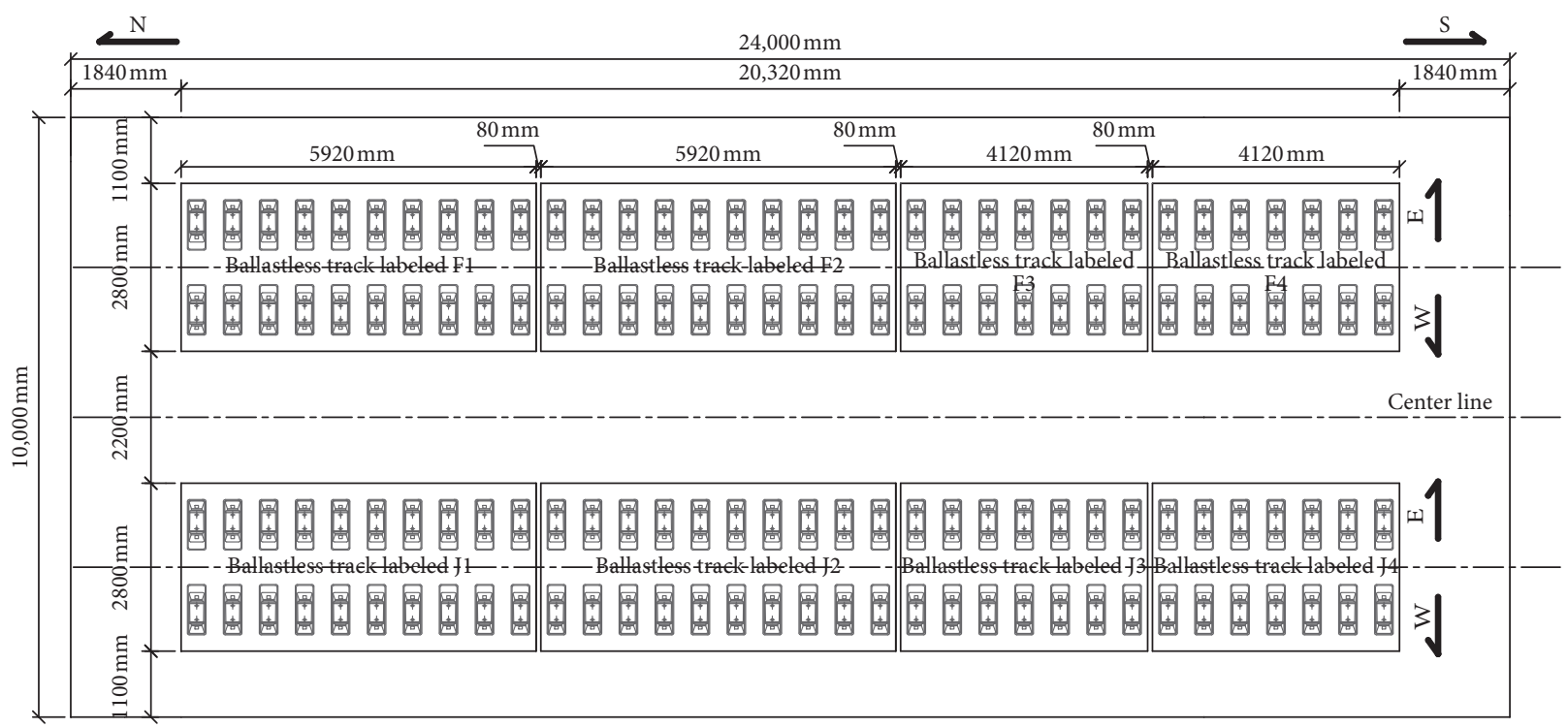

(a)

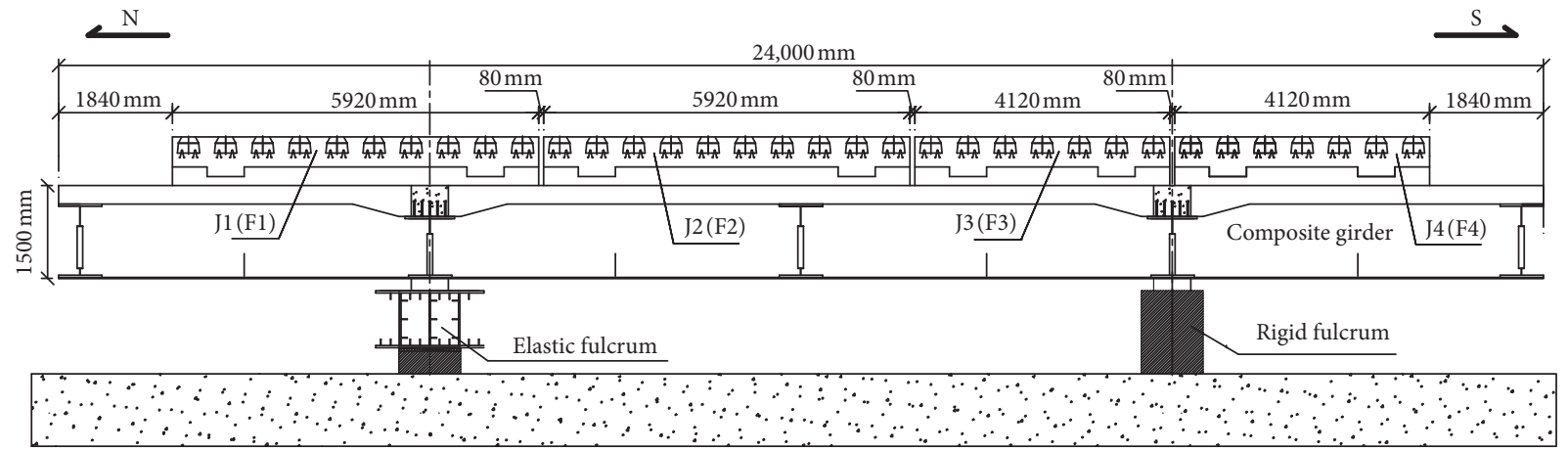

(b)

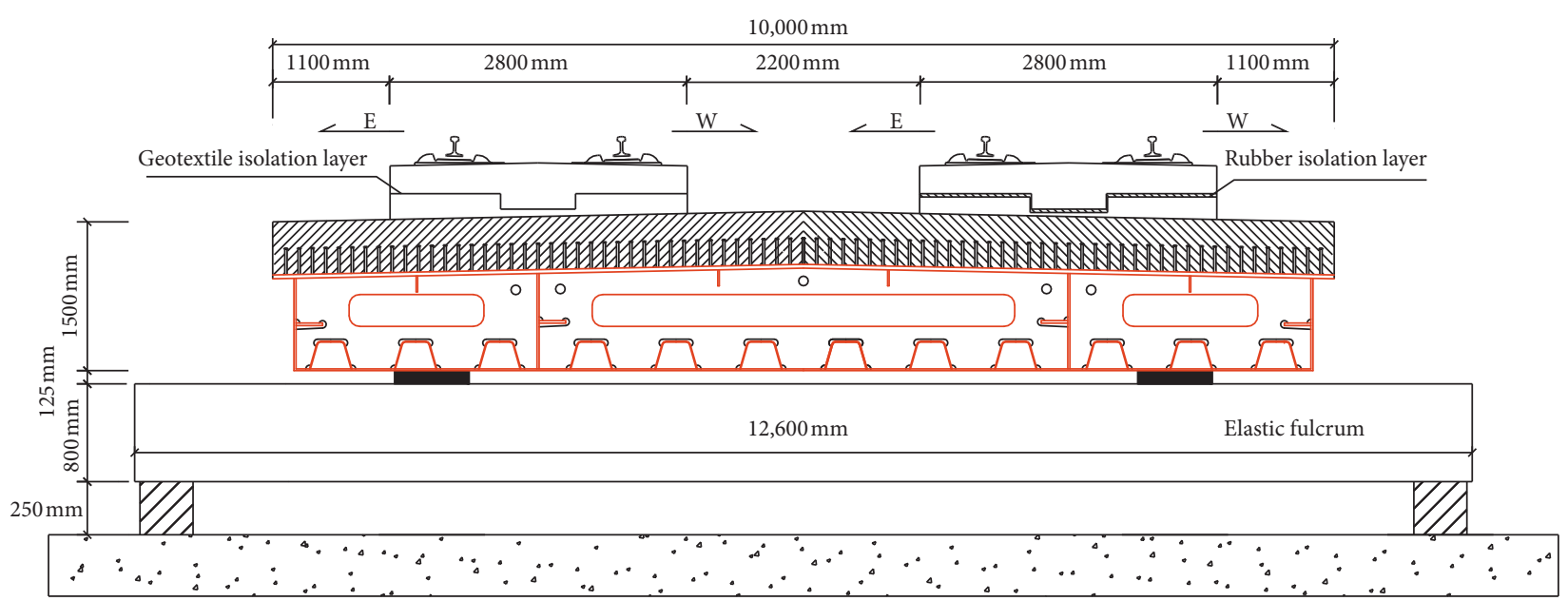

(c)

FIGURE 3: Structures of the segment model and unballasted tracks. (a) Top view of the segment model and unballasted tracks. (b) Side view of the segment model and unballasted tracks. (c) Front view of the segment model and unballasted tracks.

bending deformation mode, the downward bending deformation mode, and the reverse bending deformation mode. Furthermore, the loading conditions of Ganjiang River Bridge included ZK live load (0.8 times of the UIC live load), main girder heating-up condition $\left(+25^{\circ} \mathrm{C}\right)$, main girder cooling-down condition $\left(-25^{\circ} \mathrm{C}\right)$, cable heating-up condition $\left(+10^{\circ} \mathrm{C}\right)$, cable cooling-down condition $\left(-10^{\circ} \mathrm{C}\right)$, bridge deck heating-up condition $\left(+10^{\circ} \mathrm{C}\right)$, and their 


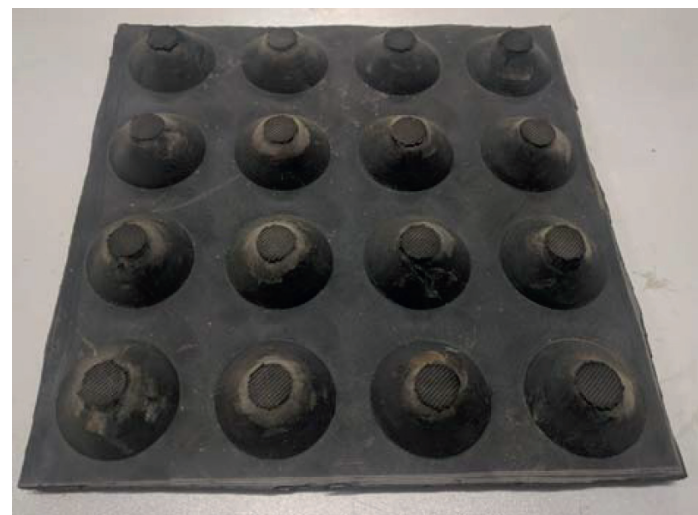

FIgURE 4: Structure of the rubber isolation layer.

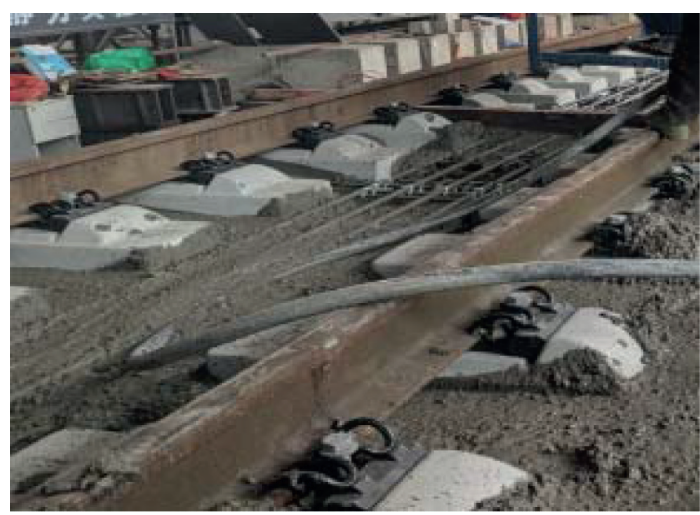

Figure 5: Unballasted tracks cast in place.

combinations according to Guidelines for Design of Highway Cable-stayed Bridge [22]. All kinds of these local deformations can be realized under different loading conditions. The local deformation of the bridge structure under each of the above loading conditions can be calculated by the finite element model (Figure 8). Based on this, the local deformation conditions of the main girder between two adjacent cables under the above loading conditions were summarized, and a total of 530 local deformation conditions were obtained. Based on this, the most disadvantageous condition of each kind of local deformation modes was selected from the above 530 local deformation conditions. In this work, one of the most disadvantageous local deformation modes of the cable-stayed bridges labeled as the maximum upward bending deformation mode was selected to research the deformation characteristics of the unballasted tracks. The maximum upward bending deformation mode was characterized by the combined action of the ZK live load and the cable heating-up condition $\left(10^{\circ} \mathrm{C}\right)$ of Ganjiang River Bridge.

\subsection{Realization of the Upward Bending Deformation} Condition. This work was to research the influence of the maximum upward bending deformation mode on the deformation characteristics of the unballasted tracks. The maximum upward bending deformation mode can be reached by multipoint loading on the segment model. Through a trial calculation on the finite element model of the
TABLE 1: Unballasted tracks used in this work.

\begin{tabular}{lccc}
\hline Categories & Label & Types of isolation layer & Length (m) \\
\hline \multirow{2}{*}{ No. 1} & J1 & Rubber & 5.92 \\
& J2 & Rubber & 5.92 \\
\hline \multirow{2}{*}{ No. 2} & J3 & Rubber & 4.12 \\
& J4 & Rubber & 4.12 \\
\hline \multirow{2}{*}{ No. 3} & F1 & Geotextile & 5.92 \\
& F2 & Geotextile & 5.92 \\
\hline \multirow{2}{*}{ No. 4} & F3 & Geotextile & 4.12 \\
& F4 & Geotextile & 4.12 \\
\hline
\end{tabular}

segment model (Figure 9), a reasonable loading scheme was obtained to simulate the maximum upward bending deformation mode. In order to reduce the differences between the testing load acted on the unballasted tracks and that of the actual load in operation, the maximum testing load in this work was not more than three times of the train axle load. Besides, a loading device suitable for the large-scale structures was designed, and a set of hydraulic jacks were used to realize the multipoint loading on the segment model (Figure 10).

In this work, six groups of the loading devices were set up on the segment model, labeled (1)-(6), respectively. The positions of each loading device were determined by the finite element analysis of the segment model, as shown in Figure 11. Through the finite element simulation of various loading schemes on the segment model, the maximum upward bending deformation condition can be achieved by loading at the locations of the loading devices (1) and (6). The load value of each loading point was $400 \mathrm{kN}$, and the twoline unballasted tracks were loaded simultaneously. Besides, the loading process was evenly divided into six steps, and the loading steps and the loading values are shown in Table 2.

The segment model was deformed under the above loading scheme to reflect the maximum upward bending deformation mode of the cable-stayed bridge. The actual deformations of the segment model, the calculated deformations of the finite element model, and the target values of the maximum upward bending deformation condition of Ganjiang River Bridge are shown in Figure 12.

From Figure 12, the maximum upward bending deformation mode of Ganjiang River Bridge was well realized by the above loading scheme. Therefore, the influence on the deformation characteristics of the unballasted tracks paved on Ganjiang River Bridge caused by the maximum upward bending deformation mode can be researched.

3.3. Arrangement of Measuring Sensors. Certainly, the deformation characteristics of the unballasted tracks are mainly reflected by interlayer behaviors such as interlayer deformations. In this work, a set of joint meters or strain gauges were used to measure the vertical interlayer deformations of the unballasted tracks. Due to the different measuring ranges of the sensors, the joint meters were used to measure the interlayer deformations of the unballasted tracks with rubber isolation layers, and the strain gauges were used to measure the interlayer deformations of the unballasted tracks with geotextile isolation layers. It should 


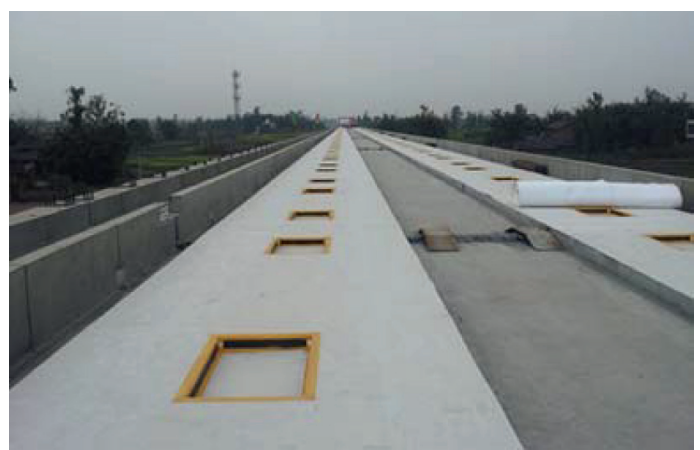

(a)

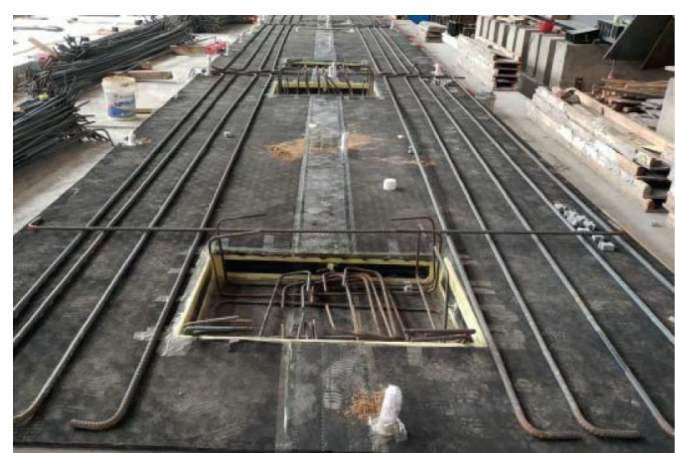

(b)

FiguRE 6: The unballasted tracks with different types of isolation layers: unballasted tracks with (a) geotextile isolation layer and (b) rubber isolation layer.

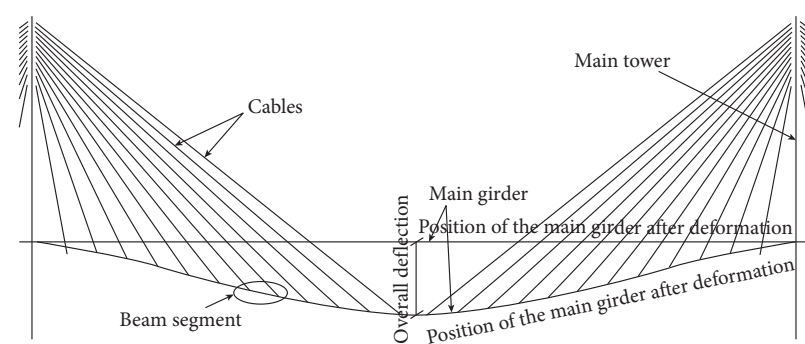

(a)

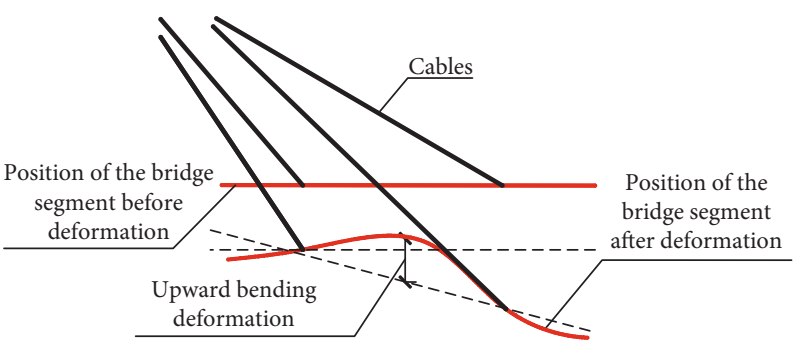

(b)

Figure 7: Deformation characteristics of the cable-stayed bridge. (a) The overall deflection of the main girder. (b) The local deformation of the beam segment.

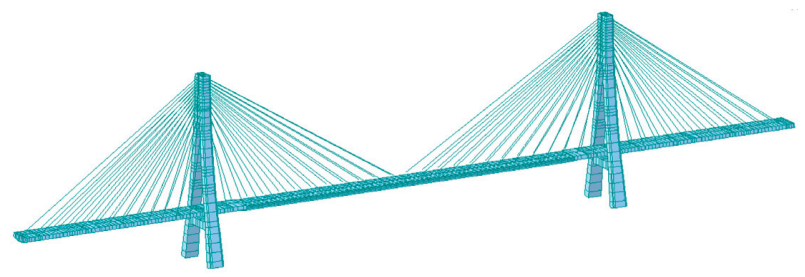

Figure 8: The finite element model of Ganjiang River Bridge.

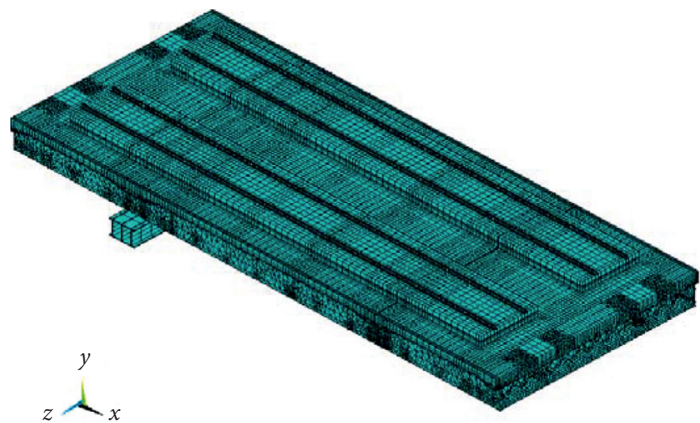

Figure 9: The finite element model of the segment model.

be particularly noted that the pre-embedded gauges should be kept vertical and protected carefully during the on-site concrete pouring process of the track slab. For the unballasted tracks with rubber isolation layers, the interlayer

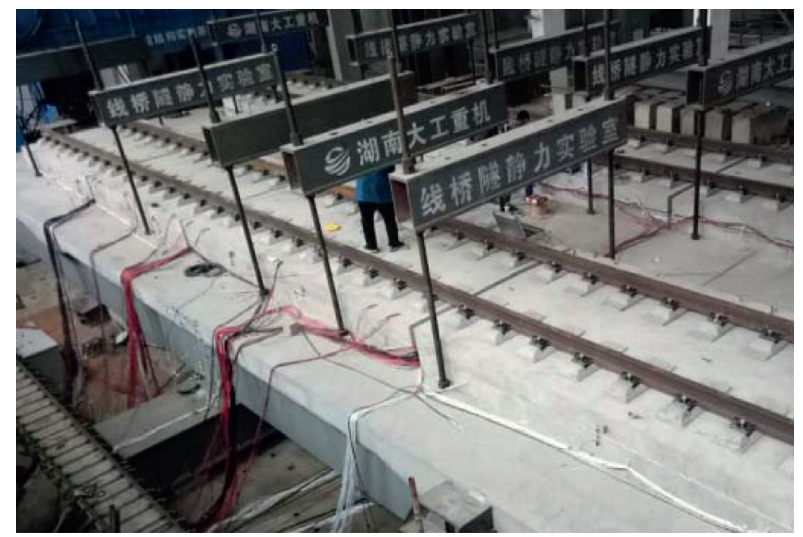

FIgURE 10: Loading devices on the segment model.

deformations can be measured directly by the embedment joint meters. However, for the unballasted tracks with geotextile isolation layers, strain gauges can be used to measure the strains within the range of the strain gauges at interlayers, so as to obtain the interlayer deformations by the strain data. This test method overcame the shortage of accuracy or difficulty in measuring the interlayer deformations of unballasted tracks, and the layouts of the deformation measuring sensors are shown in Figure 13.

For each of the unballasted tracks in this work, six embedment joint meters or six strain gauges were arranged 


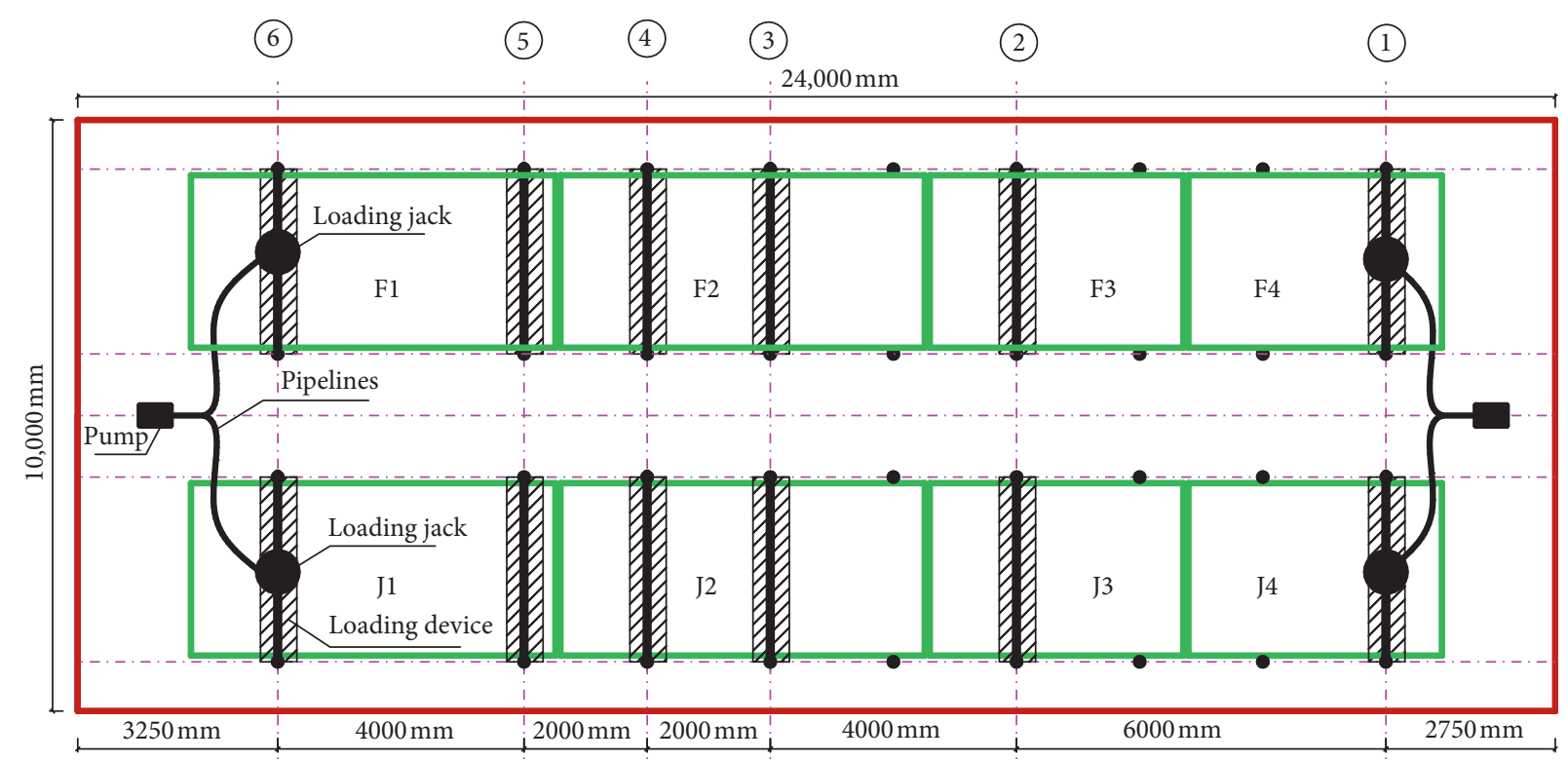

Figure 11: Arrangement of loading devices on the segment model.

TABLE 2: Multipoint loading scheme and loading values.

\begin{tabular}{|c|c|c|c|c|c|c|c|}
\hline No. & Load values $(\mathrm{kN})$ & Step $1(0 \%)$ & Step $2(20 \%)$ & Step $3(40 \%)$ & Step $4(60 \%)$ & Step $5(80 \%)$ & Step $6(100 \%)$ \\
\hline (1) & $400 \times 2$ & 0 & $80 \times 2$ & $160 \times 2$ & $240 \times 2$ & $320 \times 2$ & $400 \times 2$ \\
\hline (2) & Null & Null & Null & Null & Null & Null & Null \\
\hline (3) & Null & Null & Null & Null & Null & Null & Null \\
\hline (4) & Null & Null & Null & Null & Null & Null & Null \\
\hline (5) & Null & Null & Null & Null & Null & Null & Null \\
\hline (6) & $400 \times 2$ & 0 & $80 \times 2$ & $160 \times 2$ & $240 \times 2$ & $320 \times 2$ & $400 \times 2$ \\
\hline
\end{tabular}

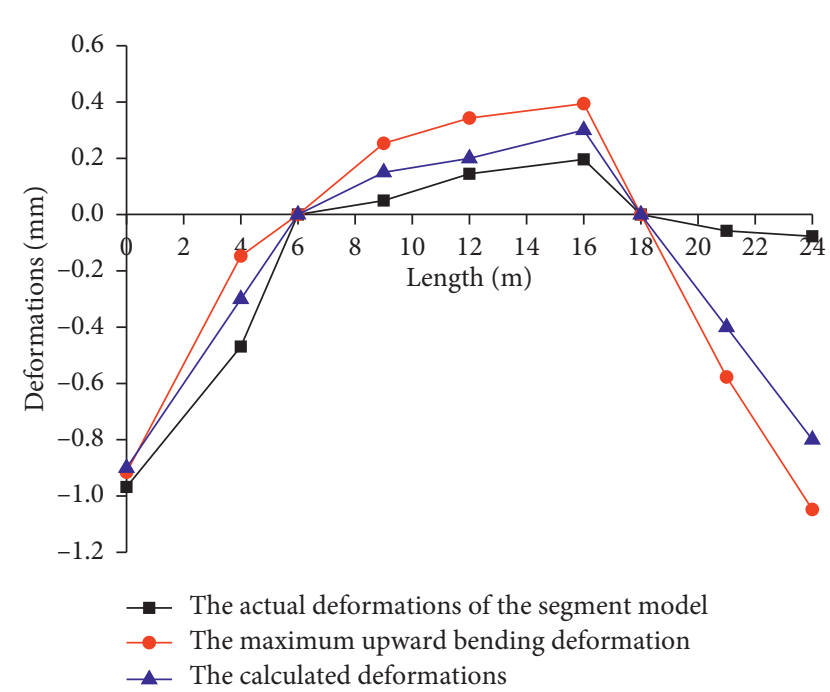

FIgURE 12: Deformation curves of the maximum upward bending deformation mode.

at interlayers. Besides, the arrangement and the nomenclature of these measuring sensors were the same for each of the unballasted tracks. These sensors were arranged into three cross sections on each of the unballasted tracks, namely, the cross section at one end of the unballasted track (cross section \#1), the cross section at the middle of the unballasted track (cross section \#2), and the cross section at the other end of the unballasted track (cross section \#3). Specifically, the arrangements of the measuring sensors are shown in Figure 14.

3.4. Test Summary. In this work, not all of the unballasted tracks paved on the segment model were loaded in the loading scheme. However, the deformation characteristics of the unballasted tracks were strongly influenced by the test loadings. Therefore, it is necessary to summarize the loading conditions of each unballasted track. The test loading acted on each unballasted track is shown in Table 3.

\section{Test Results and Discussion}

4.1. Interlayer Behaviors of Unballasted Tracks. Based on the measured data of the sensors at cross section \#3 of the unballasted track labeled $\mathrm{J} 4$, the load-deformation curves were obtained to investigate the interlayer behaviors of unballasted tracks. The interlayer loading-deformation curves are shown in Figure 15.

As shown in Figure 15, the nonlinear characteristics of the interlayer deformation of the unballasted track with the rubber isolation layer become more apparent with the increase of the test loading. The circular structures of the rubber isolation layer are compressed with the test loading increased, and then the contact areas 

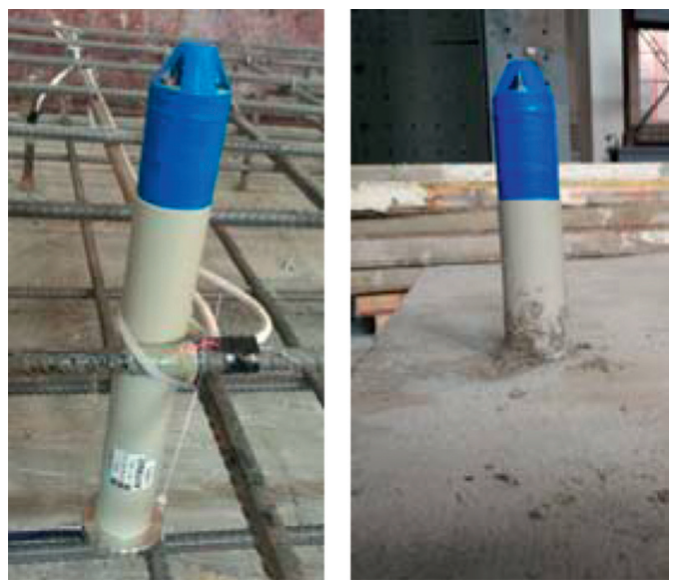

(a)
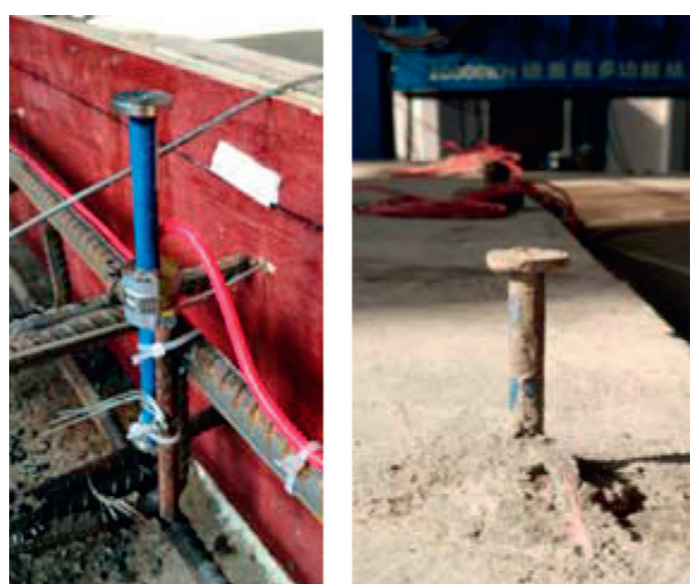

(b)

FIGURE 13: Layout of the measuring sensors. (a) Layout of embedment joint meters. (b) Layout of strain gauges.

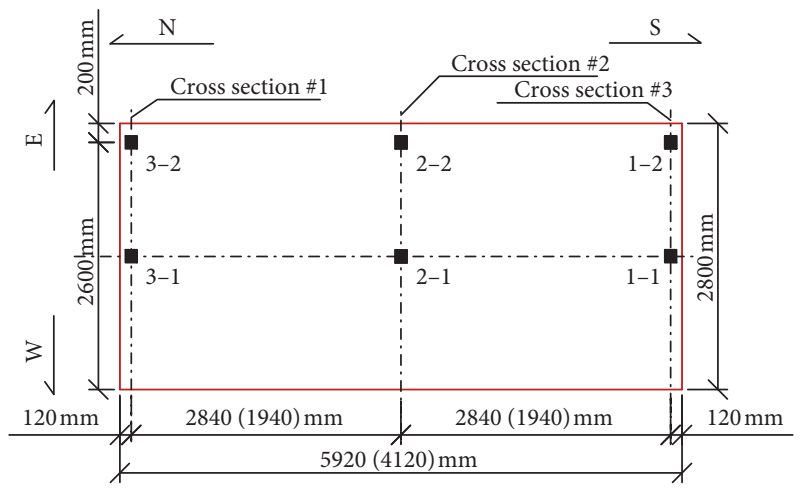

Figure 14: Measuring sensor arrangement.

TABLE 3: Test loading acted on the unballasted tracks.

\begin{tabular}{lccc}
\hline Label & $\begin{array}{c}\text { Distance between the test loading and the cross sections } \\
\text { (unit: } \mathrm{m} \text { ) }\end{array}$ \\
& Cross section \#1 & Cross section \#2 & Cross section \#3 \\
\hline J1 & 1.28 & 1.44 & 4.52 \\
F1 & 1.28 & 1.44 & 4.52 \\
J2 & Null & Null & Null \\
F2 & Null & Null & Null \\
J3 & Null & Null & Null \\
F3 & Null & Null & Null \\
J4 & 2.98 & 1.10 & 0.78 \\
F4 & 2.98 & 1.10 & 0.78 \\
\hline
\end{tabular}

between the isolation layers and the other structures increased, which led to the increasing compressive stiffness. However, the nonlinearity is not significant within the standard axle load of a train in China $(170 \mathrm{kN})$, and the interlayer deformations of the unballasted track with the rubber isolation layer are not large, which are generally not more than $2 \mathrm{~mm}$. Therefore, reasonable arrangement of the rubber isolation layers can provide appropriate elasticity at interlayers, so as to improve the interlayer behaviors of unballasted tracks.

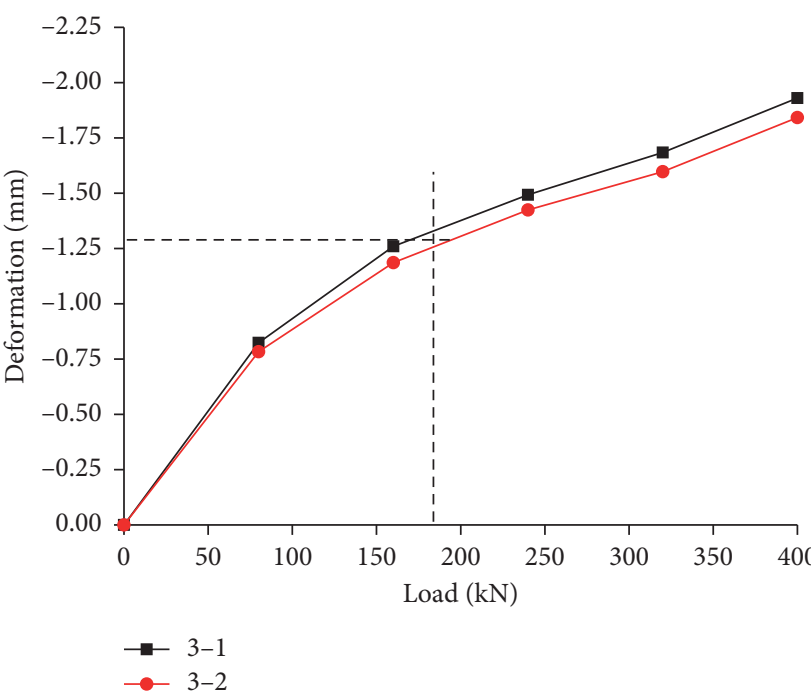

Figure 15: Load-interlayer deformation curves of unballasted tracks labeled $\mathrm{J} 4$.

4.2. Deformation Characteristics of Unballasted Tracks. Obviously, the unballasted tracks paved on the segment model deformed along with the deformations of the segment model. The interlayer deformations of the unballasted tracks paved on the segment model were summarized to investigate their deformation characteristics under the action of the maximum upward bending deformation mode. The measuring interlayer deformations of each unballasted track in this work are listed in Table 4. In Table 4, the negative values indicated the compressive deformations at interlayers, the positive values indicated the tensile deformations at interlayers, and the Nulls indicated the failures of the measuring sensors.

As we can see from Table 4, there will be some significant compressions as well as a small number of tensile deformations that occurred at interlayers of the unballasted tracks with the testing loads acted (labeled as J1, F1, J4, and F4). Besides, the interlayer deformations of the unballasted tracks 
TABLE 4: Interlayer deformations of the unballasted tracks.

\begin{tabular}{lcccccc}
\hline \multirow{2}{*}{ Label } & \multicolumn{6}{c}{ Data of the deformation measuring sensors (unit: mm) } \\
& $1-1$ & $1-2$ & $2-1$ & $2-2$ & $3-1$ & $3-2$ \\
\hline J1 & -0.904 & -0.949 & -0.424 & -0.367 & 0.198 & 0.189 \\
F1 & Null & Null & Null & -0.035 & -0.017 & 0.012 \\
J2 & 0.037 & 0.019 & 0.018 & Null & -0.039 & -0.044 \\
F2 & -0.009 & -0.004 & -0.010 & 0.005 & -0.013 & -0.007 \\
J3 & -0.007 & -0.030 & 0.011 & 0.005 & 0.039 & Null \\
F3 & -0.007 & 0.002 & -0.006 & 0.003 & -0.006 & 0.002 \\
J4 & Null & Null & -0.893 & -0.865 & -2.030 & -1.882 \\
F4 & Null & Null & Null & Null & Null & Null \\
\hline
\end{tabular}

with rubber isolation layers are much larger than those of the unballasted tracks with geotextile isolation layers. Moreover, for the unballasted tracks without any load acted (labeled as J2, F2, J3, F3), that is, these unballasted tracks always deformed along with the deformations of the segment model. Whether rubber or geotextile isolation layers are used in the unballasted tracks, there will be tiny amounts of tensile and compressive deformations occurring at interlayers of the unballasted tracks paved on the segment model, and the deformations of the rubber isolation layer are slightly larger than those of the geotextile isolation layer due to the low stiffness of the rubber material. Besides, the deformation followability of the unballasted tracks with $4 \mathrm{~m}$ in length is slightly better than that of the unballasted tracks with $6 \mathrm{~m}$ in length.

Due to some tensile deformations occurring at interlayers, the structural diseases such as voids and slits were likely brought out, which should be avoided [23]. Meanwhile, the excessive compressive deformations at interlayers always affected the rail alignment and the train operation. For the isolation layers in unballasted tracks, it might produce a certain amount of precompressive deformations during the construction process due to the deadweight of their upper structures, including the track slab and rails. Based on this, the precompression of the rubber isolation layer used in this work is $0.4 \mathrm{~mm}$. However, the precompression of the geotextile isolation layer is generally not taken into consideration. Therefore, under the maximum upward bending deformation, the maximum magnitude of the tensile deformations at interlayers of the unballasted tracks with rubber isolation layers does not exceed the precompression of the rubber isolation layer, and there will be no void and silt formed at interlayers. However, it is entirely possible to form diseases at interlayers of the unballasted tracks with geotextile isolation layers. In all, it is necessary to set the reasonable stiffness of the isolation layers, so as to control the tensile and compressive deformations at interlayers of the unballasted tracks paved on cable-stayed bridges.

\section{Conclusions}

In this work, we built a segment model to research the deformation characteristics of the unballasted tracks, which are designed to pave on cable-stayed bridges. The maximum upward bending deformation mode of a cable-stayed bridge was realized by multipoint loading on the segment model, and the interlayer deformations of the unballasted tracks paved on the segment model were summarized and analyzed. The main conclusions are as follows:

(1) The nonlinear characteristics of the rubber isolation layer are apparent due to its irregular shapes. Besides, the interlayer deformations of the unballasted track with the rubber isolation layer are less than $2 \mathrm{~mm}$ under the action of the standard train axle load.

(2) Under the maximum upward bending deformation, some tensile deformations occurred at interlayers of the unballasted tracks. The magnitude of the tensile deformations does not exceed the precompression of the rubber isolation layer, and there will be no void and silt formed at interlayers of the unballasted tracks with rubber isolation layers.

(3) Because geotextile isolation layers have no precompression to regulate the interlayer tensile deformations, some diseases such as void and silt are entirely possible to form at interlayers of the unballasted tracks with geotextile isolation layers.

(4) It is necessary to install an elastic isolation layer in the unballasted tracks paved on the cable-stayed bridge to improve their interlayer deformation behaviors. This allows for a reduction in deterioration, and an increase in the durability and quality of the unballasted tracks due to a particular elastic buffer is provided at interlayers.

\section{Data Availability}

The data used to support the findings of this study are available from the corresponding author upon request.

\section{Conflicts of Interest}

The authors declare that they have no conflicts of interest.

\section{Acknowledgments}

The authors would like to thank the financial sponsorship provided by China Railway Corporation (2015G001-G).

\section{References}

[1] C. Esveld, "Recent developments in slab track," European Railway Review, vol. 9, pp. 81-85, 2003.

[2] P.-E. Gautier, "Slab track: review of existing systems and optimization potentials including very high speed," Construction and Building Materials, vol. 92, pp. 9-15, 2015.

[3] G. L. Dai, H. Ge, W. S. Liu, and Y. F. Chen, "Interaction analysis of continuous slab track on long-span continuous high-speed rail bridges," Structural Engineering and Mechanics, vol. 63, no. 6, pp. 713-723, 2017.

[4] E. Poveda, R. C. Yu, J. C. Lancha, and G. Ruiz, "A numerical study on the fatigue life design of concrete slabs for railway tracks," Engineering Structures, vol. 100, pp. 455-467, 2015.

[5] L. Sun, L. Chen, and H. H. Zelelew, "Stress and deflection parametric study of high-speed railway CRTS-II ballastless track slab on elevated bridge foundations," Journal of 
Transportation Engineering, vol. 139, no. 12, pp. 1224-1234, 2013.

[6] Z. P. Zeng, J. D. Wang, S. W. Shen, P. Li, A. A. Shuaibu, and W. Wei-dong, "Experimental study on evolution of mechanical properties of CRTS III ballastless slab track under fatigue load," Construction and Building Materials, vol. 210, pp. 639-649, 2019.

[7] L. Zhou, L. Yang, Z. Shan, X. Peng, and A. D. Mahunon, "Investigation of the fatigue behaviour of a ballastless slab track-bridge structural system under train load," Applied Sciences, vol. 9, no. 17, p. 3625, 2019.

[8] Q. Fu, Y. Xie, G. Long, D. Niu, H. Song, and X. Liu, "Impact characterization and modelling of cement and asphalt mortar based on SHPB experiments," International Journal of Impact Engineering, vol. 106, pp. 44-52, 2017.

[9] R. Chen, X. Zhao, Z. Wang, H. Jiang, and X. Bian, "Experimental study on dynamic load magnification factor for ballastless track-subgrade of high-speed railway," Journal of Rock Mechanics and Geotechnical Engineering, vol. 5, no. 4, pp. 306-311, 2013.

[10] X. Sheng, W. Zheng, and Z. Zhu, "Mechanical behaviors and fatigue performances of ballastless tracks laid on long-span cable-stayed bridges with different arrangements," Sensors, vol. 19, no. 19, p. 4195, 2019.

[11] X. H. He, X. W. Sheng, A. Scanlon, D. G. Linzell, and X. D. Yu, "Skewed concrete box girder bridge static and dynamic testing and analysis," Engineering Structures, vol. 39, pp. 38-49, 2012.

[12] Y. Yang, G. Wu, Z.-S. Wu, T. Zhang, and Q.-D. Yang, "An experimental study of the insulation performance of ballastless track slabs reinforced by new fiber composite bars," Construction and Building Materials, vol. 83, pp. 7-18, 2015.

[13] A. Safat, R. Gianluca, and V. Zora, "Full-scale long-term experiments of simply supported composite beams with solid slabs," Journal of Constructional Steel Research, vol. 67, no. 3, pp. 308-321, 2011.

[14] M. Zhou, Y. Liu, W. Deng, M. F. Hassanein, and H. Zhang, "Transverse analysis of full-scale precast segmental box girder segments with corrugated steel webs: experimental tests and FE modelling," Engineering Structures, vol. 187, pp. 231-241, 2019.

[15] M. Tarifa, X. Zhang, G. Ruiz, and E. Poveda, "Full-scale fatigue tests of precast reinforced concrete slabs for railway tracks," Engineering Structures, vol. 100, pp. 610-621, 2015.

[16] The Third Railway Survey and Design Institute Group Corporation, TB 10621-2014: Code for Design of High Speed Railway, China Railway Publishing House, Beijing, China, 2014, in Chinese.

[17] M. Sol-Sánchez, F. Moreno-Navarro, and M. C. RubioGámez, "The use of elastic elements in railway tracks: a state of the art review," Construction and Building Materials, vol. 75, pp. 293-305, 2015.

[18] S. K. Navaratnarajah and B. Indraratna, "Use of rubber mats to improve the deformation and degradation behavior of rail ballast under cyclic loading," Journal of Geotechnical and Geoenvironmental Engineering, vol. 143, no. 6, Article ID 04017015, 2017.

[19] China State Railway Group Co., Ltd., TJ/GW 114-2013: Temporary Technical Conditions of EPDM Elastic Buffer Cushion for CRTS III Plate Ballastless Track of High Speed Railway, China Railway Publishing House, Beijing, China, 2013, in Chinese.

[20] UIC (Union International of Railway), UIC Code 719-1R, Recommendations for the Use of under Ballast Mats, VII Way and Works, UIC, Paris, France, 1st edition, 2011.
[21] General Administration of Quality Supervision and Inspection and Quarantine of the People's Republic of China, GB/T 13760-2009: Geosynthetics-Sampling and Preparation of Test Specimens, Standards Press of China, Beijing, China, 2009.

[22] Ministry of Transport of the People's Republic of China, JTG/ T D65-01-2007: Guidelines for Design of Highway CableStayed Bridge, China Communications Press Co., Ltd., Beijing, China, 2007.

[23] C. Y. Yu, J. Xiang, and Y. Zhou, "Effect of gap on vertical deformation and deterioration stress of CRTS-I ballastless track," International Journal of Materials and Structural Integrity, vol. 12, no. 1-3, p. 76, 2018. 